\title{
Privacy in India: Attitudes and Awareness
}

\author{
Ponnurangam Kumaraguru and Lorrie Cranor \\ School of Computer Science, Carnegie Mellon University, \\ 5000 Forbes Avenue, \\ Pittsburgh, PA, 15213, USA \\ \{ponguru, lorrie\}@CS.Cmu.edu
}

\begin{abstract}
In recent years, numerous surveys have been conducted to assess attitudes about privacy in the United States, Australia, Canada, and the European Union. Very little information has been published about privacy attitudes in India. As India is becoming a leader in business process outsourcing, increasing amounts of personal information from other countries is flowing into India. Questions have been raised about the ability of Indian companies to adequately protect this information. We conducted an exploratory study to gain an initial understanding of attitudes about privacy among the Indian high tech workforce. We carried out a written survey and one-on-one interviews to assess the level of awareness about privacy-related issues and concern about privacy among a sample of educated people in India. Our results demonstrate an overall lack of awareness of privacy issues and less concern about privacy in India than has been found in similar studies conducted in the United States.
\end{abstract}

\section{Introduction}

As India is becoming a leader in business process outsourcing, increasing amounts of personal data from other countries are flowing into India. India's outsourcing business brought in \$12 billion in 2003 and was expected to grow by 54 percent in 2004. The Indian outsourcing industry currently employs over 770,000 people and is expected to employ 2 million people by 2008 [16]. However, as the lack of privacy legislation in India may limit future growth, the industry is pushing for data protection laws [1], [7] [41]. Outsourced jobs often involve handling of personal information and sensitive data, including financial records and account information, and medical records [15]. While concerns have been raised about whether data privacy and confidentiality can be adequately maintained in a country that lacks privacy laws [1], [41], little is known about the privacy attitudes of the Indian workers who handle this data.

Many privacy surveys have been conducted in the United States, Europe, Australia, and Canada [22], [26], [27], [32], [45] but little information is available about privacy concerns in India. We conducted an exploratory study to gain an initial understanding of attitudes about privacy among the Indian high tech workforce. We carried out a written survey and one-on-one interviews to assess the level of awareness about privacy-related issues and concern about privacy among a sample of edu- 
cated people in India. We also reviewed privacy policies at Indian web sites to understand the types of privacy protections being offered by Indian companies.

The remainder of this paper is organized as follows: In the next section, we present a general overview of the status of privacy in India. In Section 3, we describe the methodology for our written survey, interviews, and web site survey. We present our results in Section 4 and discuss limitations and future work in Section 5.

\section{India Today}

India is the world's second most populous country, with about 1 billion inhabitants and a population growth rate of $1.44 \%$ annually as of July 2004 . India is a country where $70 \%$ of the population lives in rural villages and $60 \%$ of the population is involved in farming and agriculture [30], [49]. The Gross Domestic Product (GDP) per capita purchasing power parity of India is about \$2,900 [49]. New technologies that have brought with them increased privacy concerns in other parts of the world have been introduced more slowly in India than in Western countries.

As shown in Figure 1, Internet penetration in India has lagged significantly behind the US. While $55.13 \%$ of the US population were Internet users in 2003 , only $1.74 \%$ of the Indian population were Internet users. The 2003 level of Internet penetration in India is similar to the level of Internet penetration in the US in 1993. In addition, there is a large difference between the US and India in deployment of both landline and mobile telephone lines. In 2003 there were 65 landline telephone lines and 47 mobile telephone lines for every 100 US inhabitants, while in India there were only 4 land line telephone lines and 1 mobile telephone line [33], [34].

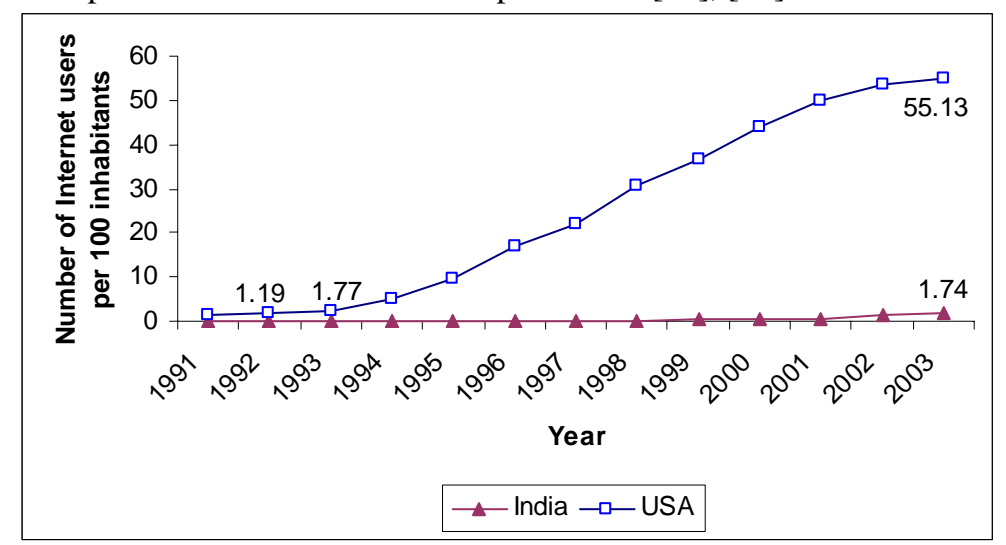

Figure 1: Internet penetration in India and the US. 


\subsection{Law}

The Constitution of India, ratified in 1950, does not explicitly recognize the right to privacy [28]. However, the Supreme Court first recognized in 1964 that there is a right of privacy implicit in Article 21 of the Constitution, which states, "No person shall be deprived of his life or personal liberty except according to procedure established by law" [43]. Here there is no mention of the word 'privacy' instead the term 'personal liberty' has been used.

There is no general data protection law in India. In May 2000, the government passed the Information Technology Act (IT Act 2000), a set of laws intended to provide a comprehensive regulatory environment for electronic commerce. However the Act has no provision for protection of personal data [13]. It has been used to argue some privacy-related cases; however, its applicability is quite limited. For example, while the IT Act 2000 does not prohibit the use of hidden surveillance cameras, it does prohibit the electronic transmittal of obscene images, including those obtained through the use of hidden cameras. With the increasing use of cell phone cameras in Indian cities, the issue of video voyeurism has been gaining significant attention [14], [42].

In the last few years there have been discussions about creating privacy laws in India. As more and more companies from other countries are conducting business in India, there is an increase in concern about the lack of privacy laws in India [44]. Proposals are being considered for a law that would mandate privacy protections for data from other countries that is handled by India's outsourcing industry [41]. In the mean time, in response to recent incidents in which Indian outsourcing industry workers allegedly used personal information about customers of US companies to steal money from those customers, India's National Association of Software and Service Companies (NASSCOM) announced in April 2005, that it has begun creating a database of all employees working in the outsourcing industry. Called "Fortress India," this database will allow employers to screen out potential workers who have criminal records [8],[37].

\subsection{Culture}

Indian culture may play a significant role in shaping attitudes about privacy. Cultural values are known to affect a population's attitudes about privacy [3], [6], [17], [39], [40]. Hofstede developed a number of cultural values indices to measure cultural differences between societies. According to Hofstede, India is a collectivist society with lower Individualism Index (IDV) and higher Power Distance Index (PDI) compared to the US, which is an individualist society with higher IDV and lower PDI. Hofstede has shown that individuals in collectivist societies have more trust and faith in other people than individuals in individualist societies [19], [20].

Anecdotal evidence of Indians' tendency to trust that their personal information will not be misused can be found in recent Indian popular press reports that Indians are largely unaware of the extent to which databases of personal information are sold and traded among companies. When informed of this practice, the press reports that 
individuals are often shocked and outraged. Recently, news magazine India Today, featured a cover story titled "Privacy on Sale," illustrated with a cover photo of a man with a bar code stamped on his head [5]. The Times of India featured a special report on "The Death of Privacy" [47]. Similar stories have been showing up in the Western press for several years, but have only recently appeared in India.

The Indian joint family tradition [48], in which it is common for households to include multiple brothers, their wives, and their children (all living in a relatively small house by US standards), results in more routine sharing of personal information among a wider group of people than is typical in the US. Information that might typically be disclosed only to one's spouse or parents in the US is more frequently shared among uncles, aunts, and cousins in India. In addition, as it is common for Indian businesses to be owned and operated by large extended families, personal financial information is typically shared fairly widely among Indians.

\section{Methodology}

Our study included a survey, mental model interviews, and a review of web site privacy policies, all conducted during the summer of 2004. The methodology we used for each part of our study is explained below.

\subsection{Survey}

We developed a survey questionnaire to provide insights into attitudes about privacy of the Indian high tech workforce and technical students. We developed our survey instrument such that questions were comparable to questions on similar surveys administered in the US [10], [11], [18], [23], [24], 25], [26], [27], [36]. We developed our survey and pre-tested it on a sample of 30 students, professors and professionals. After refining our survey, we distributed 550 survey questionnaires at 12 companies and three universities in two Indian cities-Chennai and Hyderabad located in two different states (TamilNadu and Andhra Pradesh). Students were given about 20 minutes of class time to complete their surveys. Surveys were left with professors and professionals, and collected about a week later. We obtained 419 completed surveys (response rate of $76 \%$ ). We eliminated surveys from 12 respondents who did not answer at least two of our six demographic questions, leaving us with 407 respondents in our sample.

Motivated by concerns about whether the Indian outsourcing industry can properly protect the personal data it handles, we decided to focus our survey on members of the Indian high tech workforce and students who might someday be employed by the outsourcing industry. Our sample included undergraduate students, graduate students, and professors from top Indian technical universities, as well as professionals. Although we did not restrict our sample to individuals currently employed by the outsourcing industry, we believe our survey respondents and interviewees have similar educational and socio-economic backgrounds as people employed by the outsourcing industry. In addition, students at the universities we surveyed are being 
recruited by the outsourcing industry. Ninety percent of our respondents were IT students or professionals.

Our sample is not statistically representative of any particular Indian community or of Indian Internet users. The average household income of our respondents was high by Indian standards, and our respondents were mostly well-educated and experienced Internet users. We believe that while not statistically representative, our sample is important for understanding workers in the outsourcing industry as well as the increasing more educated Indian high tech workforce. Table 1 summarizes the demographics of our sample.

Table 1 : Characteristics of the sample (Annual Income calculated with \$ $1=$ Rs.45).

\begin{tabular}{|l|l|}
\hline & $\mathrm{N}=407$ \\
\cline { 2 - 2 } & Percentage \\
\hline Age & \\
\hline Less than 18 years & 3.44 \\
\hline 18 - 24 years & 60.20 \\
\hline 25 - 29 years & 22.36 \\
\hline 30 - 39 years & 10.57 \\
\hline $40-49$ years & 1.47 \\
\hline $50-64$ years & 1.47 \\
\hline No answer & 0.49 \\
\hline Sex & \\
\hline Male & 75.68 \\
\hline Female & 24.32 \\
\hline No answer & 0.00 \\
\hline Education & \\
\hline Less than High school & 0.25 \\
\hline Higher School & 8.85 \\
\hline Some College & 6.14 \\
\hline College Graduate & 49.39 \\
\hline Post Graduation & 33.42 \\
\hline Doctorate & 1.23 \\
\hline No answer & 0.74 \\
\hline Household annual income & \\
\hline Less than \$890 & 10.57 \\
\hline Between \$891 and \$1560 & 10.07 \\
\hline Between \$1561 and \$2220 & 9.83 \\
\hline Between \$2221 and \$3330 & 11.30 \\
\hline Between \$3331 and \$4440 & 10.57 \\
\hline Greater than \$4441 & 26.54 \\
\hline No answer & 21.13 \\
\hline Profession & \\
\hline Computer related & 45.45 \\
\hline Manufacturing & 0.00 \\
\hline Teaching / Research & 7.13 \\
\hline Student & 44.72 \\
\hline Others & 2.70 \\
\hline
\end{tabular}

\subsection{Interviews}

We conducted one-on-one interviews to gain insights into the mental models people hold about privacy [35], [38]. We recorded interviews with 29 subjects and produced 
text transcripts. The interviews contained 17 open ended questions organized in several categories: general understanding of privacy and security, security and privacy of computerized data, knowledge of risks and protection against privacy risks, knowledge of data sharing and selling in organizations and government, and demographics. No personal information (name, email address, etc.) that would re-identify any individual was collected. We also used randomly generated numbers to identify the subjects in our notes so that the privacy of the subjects can be completely maintained.

Subjects were recruited who were at least 23 years old, with at least a Bachelor's degree, and at least 6 months work experience. The interviews were conduced in Chennai and Hyderabad, but many of the subjects were originally from other cities in India. Sixty-two percent of the subjects were male and $38 \%$ were female. The subjects ranged in age from 23 to 65 (75\% were in the $23-35$ category and $25 \%$ were in the 36-65 category). The average work experience was nine years. Thirty-one percent of subjects had only a bachelor's degree while others held graduate or professional degrees. Thirty-eight percent of subjects work in technical fields while $62 \%$ work in non-technical fields such as linguistics, accounting, and the arts. In this paper we refer only briefly to this interview study. A complete report of this study will be published elsewhere.

\subsection{Website Privacy Policy Survey}

We surveyed 89 web sites selected from the Google Indian shopping directory to determine whether they included privacy policies and what privacy protections were offered. At the time of our survey in the summer of 2004, 94 web sites were listed in this directory; however, five were unreachable [21]. For each privacy policy that we found, we recorded detailed information about the policy, (similar to the information gathered by Adkinson et al in their 2001 survey of American web sites [2]) including whether the site had a privacy seal, whether there was a corresponding P3P policy, whether the site collected personal information, whether the site shared personal information with third parties, and the choice options provided.

We selected the Google Indian shopping directory because it provides a list of ecommerce web sites that primarily serve the Indian market. Because most commercial Indian web sites have .com domains, they are difficult to identify, and whois information is not always a reliable indicator as to the market served. In future work it would be useful to survey the most popular web sites actually visited by people connecting to the Internet from India, although we expect that the most popular site list is dominated by non-Indian sites.

\section{Analysis}

In this section, we present our analysis of general privacy concerns, posting personal information, comfort level sharing different types of data, web privacy policies, trust in businesses and government, and web cookies. 
We found no statistically significant differences between men and women, or between students and professionals, in the responses to the questions presented here. Therefore, we provide only the results for the complete set of 407 respondents. Throughout this paper we report our results as valid percentages. ${ }^{1}$

\subsection{General Privacy Concerns}

Alan Westin has used a number of standard survey questions about privacy concern to track changing attitudes about privacy in America since 1970 [51]. Similar questions have also been asked on other surveys [10].

We included a number of questions on our survey that had been included on Westin's surveys and other surveys of American Internet users. One question asked subjects to report their level of concern about personal privacy, and another asked subjects to report their level of concern about personal privacy on the Internet. Seventy-six percent of Indian respondents were very or somewhat concerned about personal privacy and $80 \%$ were very or somewhat concerned about personal privacy on the Internet.

We compared our results with the results of a 1998 AT\&T study of American Internet users drawn from a panel of readers of FamilyPC magazine, and found overall a lower level of concern among the Indian sample than among the American sample, as shown in Figure 2. Although we are comparing results of surveys administered over five years apart, we believe this comparison is still useful. The trend across several American surveys administered between 1994 and 2003 has been towards increasing levels of general privacy concern [25]. However, as individuals gain more Internet experience, their concerns about online privacy tend to decrease [3]. By comparing our sample with an earlier US sample, we are able to do a comparison between individuals with similar levels of Internet experience. In our sample, $27 \%$ of respondents had used the Internet for five years or more, and $16 \%$ had used it for two years or less. In the AT\&T sample, $28 \%$ of respondents had used the Internet for five years or more and $23 \%$ had used it for two years or less. In addition, $67 \%$ of our respondents said they used the Internet several times a day and 13\% said they used it once a day. In the AT\&T sample, $65 \%$ said they used the Internet several times a day and $18 \%$ said they used it once a day.

${ }^{1}$ Valid percent is the percentage calculated after removing those surveys that had missing answers for the particular question. The complete questionnaire and the responses for each question can be obtained from the authors upon request. 


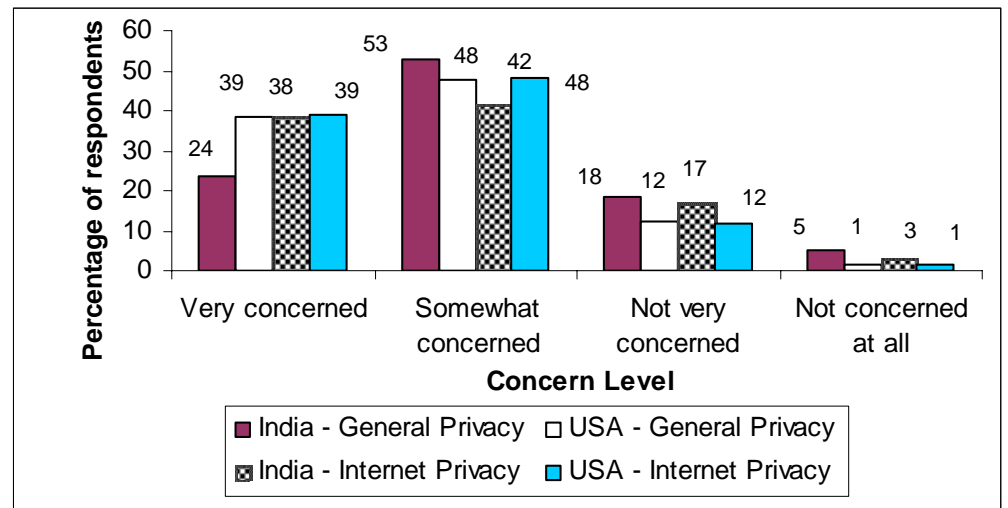

Figure 2: General and Internet privacy concern in India, compared with 1998 survey of American Internet users [10]

\subsection{Posting Personal Information}

We asked several questions to gauge attitudes about common situations in India in which personal information is not well protected. Two of these situations involve the posting of personal information in public places.

One question asked students whether they were concerned about the posting of students' grades along with their full names on public notice boards on university campuses. This remains a common practice in India, although American universities now prohibit it (indeed, the practice is illegal for federally-funded institutions under the Family Educational Rights and Privacy Act). Some Indian universities even post grades on public web sites [29]. We found that $21 \%$ of the respondents we surveyed were very concerned and $32 \%$ were somewhat concerned about their university grades being posted, while $27 \%$ were not very concerned and $20 \%$ were not concerned at all. During discussions with Indian professors we found that many of them were aware that American universities do not publicly post student grades, and some had even unsuccessfully tried to convince their own universities to consider changing their policies on posting grades. While the survey and interviews indicate some level of awareness and concern about this practice, this was not a major concern of most of the people we surveyed.

We also asked respondents about the practice of publicly posting personal information about travelers at Indian railway stations and in train compartments, as shown in Figure 3. The posted information includes the last name, first name, age, gender, boarding station, destination, seat number, and passenger name record number for each passenger. We found even lower levels of concern about this practice than of the public posting of grades. The responses to our questions about public posting of personal information are summarized in Table 2. 


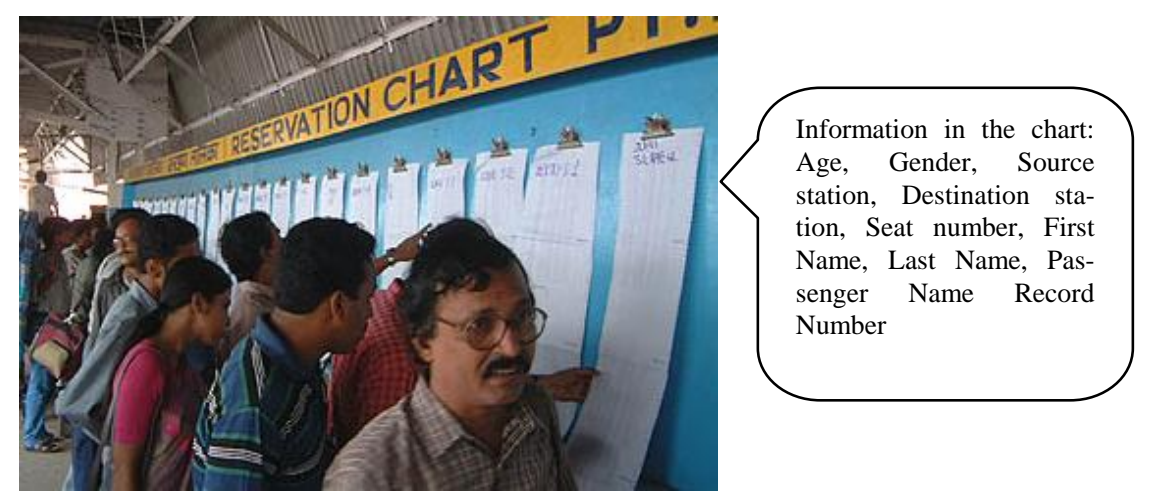

Figure 3: People checking the reservation charts at an Indian railway station [4].

Table 2. Level of concern about public posting of personal information

\begin{tabular}{|c|c|c|}
\hline & $\begin{array}{c}\text { Concern about public } \\
\text { posting of grades }\end{array}$ & $\begin{array}{c}\text { Concern about the } \\
\text { railway posting } \\
\text { personal information }\end{array}$ \\
\hline Very concerned & $21 \%$ & $17 \%$ \\
\hline Somewhat concerned & $32 \%$ & $23 \%$ \\
\hline Not very concerned & $27 \%$ & $34 \%$ \\
\hline Not concerned at all & $20 \%$ & $26 \%$ \\
\hline
\end{tabular}

\subsection{Comfort Level Sharing Different Types of Data}

We asked respondents how comfortable they were providing nine specific pieces of information to web sites. We found significant differences in comfort level across the nine types of information. Respondents were most comfortable sharing their age, email address, and health information with web sites. They were least comfortable sharing credit card number, passport number, email and ATM passwords, and annual income.

The 1998 AT\&T survey asked a similar question about seven of the nine pieces of information we asked about [10]. Figure 4 compares our results with the AT\&T survey results. Overall, our Indian respondents showed a greater level of comfort in sharing personal information with web sites than the American respondents. We expect that a 2004 survey of American Internet users would show increased comfort with sharing some types of information due to increased Internet experience, but lower comfort sharing email address as a result of concerns about spam, which was not nearly as big a problem in 1998. Only 38\% of our Indian sample said they were somewhat or very concerned about spam, while $94 \%$ of American Internet users surveyed in 2001 said spam was a concern [26]. 


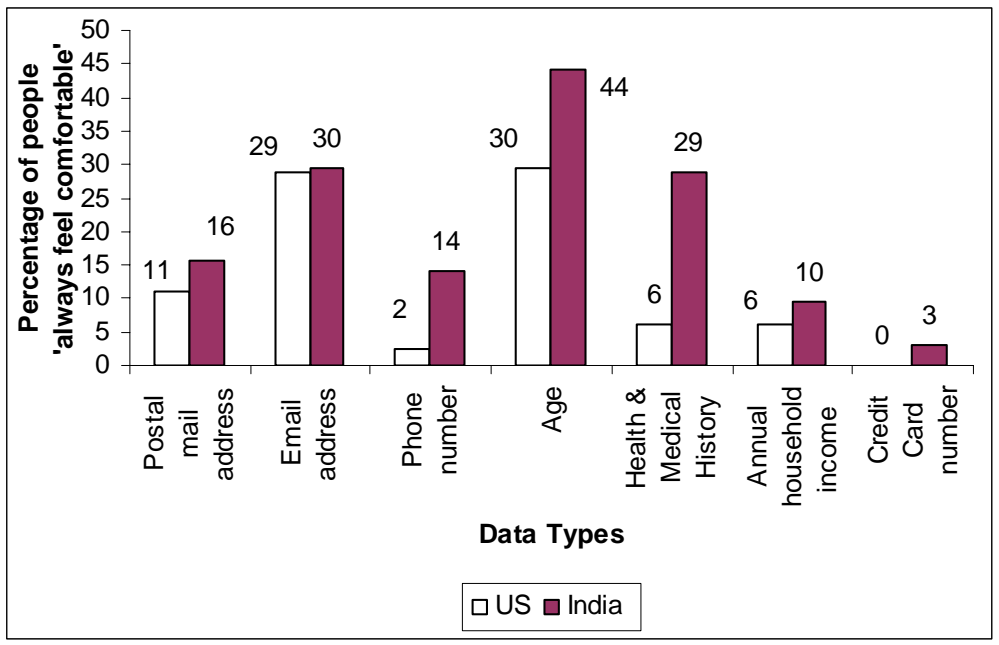

Figure 4 : Level of concern sharing different data with web sites, Indian survey compared with 1998 survey of American Internet users [10]

The most striking difference between the AT\&T survey and our Indian survey is found in the level of comfort people have in sharing health and medical information with web sites. While $29 \%$ of our respondents always feel comfortable sharing health information with web sites, only $6 \%$ of respondents in the AT\&T study said they always feel comfortable sharing this information. Likewise, 33\% of respondents in the AT\&T study and $21 \%$ of respondents in our study never feel comfortable sharing health information with web sites. More work is needed to understand why Indians are more comfortable sharing health information than Americans; however, we suspect it may have to do with Americans' concerns about job discrimination and health insurance. Few Indian workers currently have health insurance.

Similar to the AT\&T study, we found significant differences in sensitivity to sharing three types of contact information: postal mail address, phone number, and email address. As shown in Table 3, our respondents were most comfortable sharing email address and least comfortable sharing phone number [10].

Table 3 : Comfort level sharing contact information with web sites

\begin{tabular}{|l|c|c|c|}
\hline & $\begin{array}{c}\text { Postal mail } \\
\text { address }\end{array}$ & Email address & Phone number \\
\hline Always feel comfortable & $16 \%$ & $30 \%$ & $14 \%$ \\
\hline Usually feel comfortable & $27 \%$ & $30 \%$ & $12 \%$ \\
\hline Sometimes feel comfortable & $29 \%$ & $27 \%$ & $26 \%$ \\
\hline Rarely feel comfortable & $16 \%$ & $8 \%$ & $20 \%$ \\
\hline Never feel comfortable & $12 \%$ & $6 \%$ & $29 \%$ \\
\hline
\end{tabular}


Our interviews provided further evidence of a relatively high level of comfort among Indians for sharing personal information. One subject said, "I am not concerned about others knowing about my physical mail address or email address but I am concerned if they get to know my credit card details.” Another commented, “... my friends and family members know most of my information including financial and medical information." A third offered a comment that seemed to capture the views of many of our subjects, “As an Indian mentality we always like to share things.”

\subsection{Web Privacy Policies}

In the US, there has been increasing pressure from the Federal Trade Commission for web sites to post privacy policies. In addition, companies in some regulated industries are required to post privacy notices. As of 2001, 83\% of US commercial web sites had posted privacy policies [2], up from 66\% in 1999 [12]. There are no requirements for Indian web sites to post privacy policies. However, as privacy policies are becoming increasingly expected on commercial web sites around the world, Indian web sites are beginning to post them. We examined 89 Indian e-commerce websites listed in the Google Indian shopping directory and found that only $29 \%$ had posted privacy policies. None of the Indian web sites were P3P (Platform for Privacy Preferences) enabled [9], while 5\% of the American web sites that collected personallyidentifiable information were P3P-enabled in 2001. Only one of the Indian web sites had a privacy seal, while $11 \%$ of American web sites had privacy seals in 2001, up from $8 \%$ in 2000 [2].

The Indian sites that posted privacy policies reported similar data practices as reported by American web sites in 2001. One of the most important differences was that Indian sites were much less likely than American sites to offer opt-out opportunities. A larger sample of Indian web sites is needed to do a meaningful comparison of more detailed online privacy practices.

Some of the privacy policies found on Indian web sites did not actually contain much information about the web site's privacy practices. For example, one privacy policy explained only the customers' responsibilities and not the company's responsibilities:

The Customers shall not disclose to any other person, in any manner whatsoever, any information relating to [this website] ... or its affiliates of a confidential nature obtained in the course of availing the services through the website. Failure to comply with this obligation shall be deemed a serious breach of the terms ....

Given that privacy policies are uncommon on Indian web sites and rarely offer consumers any choices, we were not surprised to find that $35 \%$ of our respondents said they never read privacy policies and only $27 \%$ or our respondents said they sometimes or always read privacy policies. A 2001 US study found that $17 \%$ of American Internet users report never reading privacy policies and 36\% report sometimes or always reading privacy policies [11]. It is unclear whether the apparently 
lower level of privacy concern in India is partially responsible for fewer Indian than American web sites posting privacy policies, or, whether the lack of Indian privacy policies is playing a role in limiting Indian awareness of privacy issues.

\subsection{Trust in Businesses and Government}

Other researchers have found that privacy concern levels tend to be correlated with distrust in companies and government [3], [36]. To understand the level of trust Indians have in companies and governments that collect personal information, our interviews included a number of questions about trust. We asked interview subjects to tell us their level of trust that both business and the government would not misuse their personal information. Subjects that gave a 0 to $30 \%$ chance of misuse of information were categorized as "highly trusting," subjects that gave a 31 to $70 \%$ chance of misuse of information were categorized as "somewhat trusting," and subjects that gave a 71 to $100 \%$ chance of misuse of information were categorized as "untrusting." Most of our subjects ( $86 \%$ for businesses, $81 \%$ for governments) were highly trusting, and very few were untrusting ( $7 \%$ for businesses, $4 \%$ for governments). Of the subjects who gave a numerical value in their responses, 13 out of 28 said there was a $0 \%$ chance that their data would be misused by businesses, and 11 out of 26 said there was a $0 \%$ chance that their data would be misused by the government. One subject said, "I believe in government, 100\% they will not abuse it." These results suggest that the level of privacy concern among our interview subjects is fairly low.

These results are quite different from the results of an American study that asked about trust of business and government (although, it should be noted that there were significant differences in the way the questions were worded). A 2001 Harris Interactive study of American Internet users found that only 10\% of people have high levels of trust for businesses and 15\% have high levels of trust for the government [23], [24].

We also asked subjects about how much they trust businesses that buy personal information from the primary data collector to use for marketing. We found that respondents had less trust in these businesses, with only $65 \%$ trusting them not to misuse their personal information.

\subsection{Web cookies}

Web cookies are used to identify repeat visitors to a web site and streamline online transaction processes. When asked about web cookies, $57 \%$ of our respondents and $52 \%$ of the AT\&T respondents said they were concerned about web cookies, and $15 \%$ of our respondents and $12 \%$ of the AT\&T respondents said they did not know what a web cookie is. Of those who knew what cookies were, $47 \%$ of our respondents and $23 \%$ of the AT\&T respondents had never changed the cookie settings from the default setting. Figure 6 shows the browser cookies settings reported by respondents who knew about web cookies and compares our results with the AT\&T study. The most significant difference between the two survey results is in the percentage of people who have never changed their cookie settings. Indian respondents were twice 
as likely to report never changing their cookie settings as the American respondents. We also saw a big difference in the percentage of respondents who configured their browser to warn about all cookies. This difference may be attributable to the increased use of cookies since 1998, making that setting quite disruptive to the browsing experience.

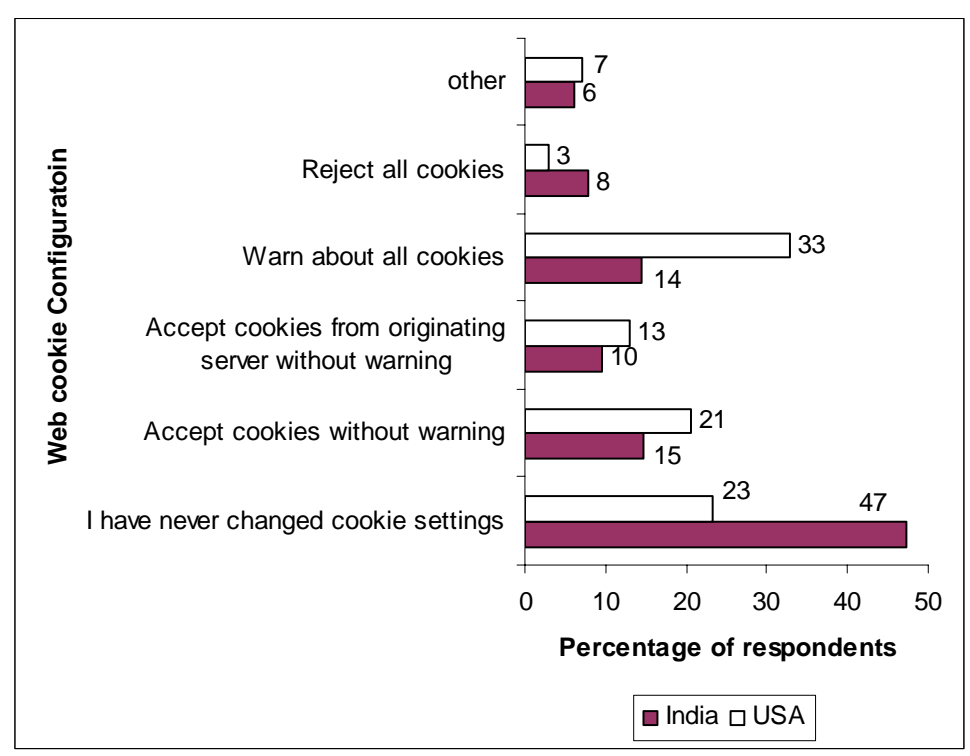

Figure 5 : Web cookie configuration reported by Indians compared with 1998 AT\&T survey [10]

We presented two scenarios in which we described the use of persistent identification numbers stored in cookies that web sites could use to track their visitors; however, we did not use the word "cookie" in our descriptions. We found that $78 \%$ of our respondents would definitely or probably agree to the use of such identification numbers to receive customized service, while $58 \%$ of our respondents would agree to the use of such identification numbers to provide customized advertising. These results are quite similar to the findings of the AT\&T study [10].

Overall, our Indian sample shows a moderate level of knowledge and concern about cookies that is not all that different from Americans in the 1998 AT\&T sample. The biggest difference is that Indians were less likely to have changed their cookie settings than Americans. This may indicate less concern, less willingness to take steps to address the cookie concern, or less knowledge about browser cookie configuration.

\section{Discussion}

As specified earlier, this study was an exploratory study to understand the attitudes of Indians about privacy and see how they differ from Americans. We conducted a writ- 
ten survey and interviews, and analyzed privacy policies on Indian web sites. Overall, we found less concern and awareness about privacy among Indians than among Americans. There were large differences in attitudes about sharing medical information as well as in willingness to trust businesses and the government with personal information. Some of these differences may be attributable to cultural differences [3], or to the fact that Internet technology has been adopted earlier in the US than in India. More research is needed to better understand the reasons for these differences.

Concerns have been raised about whether the Indian outsourcing industry can properly protect personal data and new privacy laws are being proposed [15], [41], [44]. Our results suggest that the Indian high tech workforce may not be sufficiently aware of privacy issues, and that the outsourcing industry and international businesses may need to provide privacy training to their workers. This training could also be a part of Indian undergraduate education.

We were unable to do a direct comparison of our results with a more recent US study, due to the fact that more recent US studies did not ask the same questions that we asked. However, as more recent US studies have shown a trend towards increasing privacy concerns [25], we believe that a comparison of our data with data from a similar study conducted in the US during the same time period would likely show larger difference in the attitudes and awareness than shown in this paper.

We were also unable to do a direct comparison of our results with the results of studies conducted in Australia and Europe due to differences in the questions asked. In general we find that our Indian responsdents are less concerned about misuse of their personal information than Australian, German, and British survey respondents [31], [46]. One Australian study found that $41 \%$ of respondents reported setting their web browsers to reject cookies, while we found only $7 \%$ of our Indian respondents reported setting their browsers to reject cookies. Furthermore, the Australians surveyed were more than twice as likely to report reading privacy policies than the Indians we surveyed. Australians also reported lower levels of trust in government, and substantially lower levels of trust in retailers than we found in our Indian subjects. Finally, the Australians demonstrated a greater awareness of privacy issues than we found among our Indian subjects [46]. We expect our results to aid future researchers in studying privacy attitudes in India and cross-cultural attitudes about privacy.

Although we obtained some interesting results that are consistent with studies of Indian cultural values, it is important to recognize the limitations of our samples. The results we obtained cannot be generalized to the entire Indian population, or even to the entire Indian high tech workforce. We also understand that the level of privacy concern reported by respondents does not necessarily correspond to their actual behavior with respect to protecting their own privacy or maintaining the confidentiality of data they handle as part of their employment [50].

Future work might attempt to survey a random national sample, or to focus specifically on workers in the outsourcing industry. A study of outsourcing workers might include questions about how they handle customer data and evaluate their knowledge of relevant privacy policies. A common study conducted in both the US and India in the same timeframe would also be useful. As the penetration of the Internet and communication technologies is now increasing rapidly in India and westerni- 
zation is having an increasing influence on Indian life, a longitudinal study involving annual surveys would be valuable.

\section{Acknowledgements}

The interview protocol used in this study was adapted from a protocol developed by Granger Morgan and Elaine Newton at Carnegie Mellon University. The authors would like to thank Raj Reddy for providing partial support for this study while the first author was a student at International Institute of Information Technology, Hyderabad, India. The authors would also like to thank Krishna Reddy T.S.V., who assisted with the website privacy policy analysis at IIIT Hyderabad. This research was partially funded by Carnegie Mellon CyLab and an IBM Faculty Award.

\section{References}

1. Achappa, Sigi. Outsourcing is a bubble in India. CIOL. October 2004. http://www.ciol.com/content/news/BPO/2004/104101402.asp.

2. Adkinson, F William, et al. Privacy Online: A Report on the Information Practices and Policies of Commercial Web sites. The Progress and Freedom. Special Report March 2002.

3. Bellman, Steven, Eric J. Johnson, Stephen J. Kobrin, and Gerald L. Lohse. "International Differences in Information privacy concerns: A global survey of consumers.” The Information Society, 20, pp 313 - 324. 2004.

4. Beveridge, Colin. Photographs of India: Kolkota during 2001. http://www.colinbeveridge.com/travelarticle.asp?article=16. visited 16 Jan 2005.

5. Bhupta, Malini. Privacy on Sale. India Today International. Sep 272004.

6. Boni, De Marco, Martyn Prigmore. Cultural Aspects of Internet Privacy. Proceedings of the UKAIS 2002 Conference. Leeds. 2002.

7. Business Line. Tech job loss will be other industries' gain. October 2004. http://www.thehindubusinessline.com/2004/10/16/stories/2004101601900500.htm.

8. Business Standard. NASSCOM to set up employee database. April 2005. http://www.nasscom.org/artDisplay.asp?art_id=4247. visited 23 April 2005.

9. Cranor, Lorrie Faith. “Web Privacy with P3P.” O'Reilly. 2002.

10.Cranor, Lorrie, Joseph Reagle, Mark S Ackerman. Beyond Concern: Understanding Net Users' Attitudes About Online Privacy. In Proceedings of the Telecommunications Policy Research Conference. Alexandria, VA. September 25-27, 1999. http://www.research.att.com/resources/trs/TRs/99/99.4/99.4.3/report.htm.

11.Culnan, Mary J, George R Milne. The Culnan-Milne Survey on Consumers \& Online Privacy Notices. http://www.ftc.gov/bcp/workshops/glb/supporting/culnan-milne.pdf. Dec 2001.

12.Culnan, Mary J. Georgetown Internet Privacy Policy Survey:Report to the Federal Trade Commission. June 1999. http://www.msb.edu/faculty/culnanm/GIPPS/mmrpt.PDF.

13.Department of Information Technology. Information Technology Act 2000. http://www.mit.gov.in/it-bill.asp. visited 10 Nov 2004.

14.Duggal, Pavan. Licence to shoot. Yahoo! India News. December 24, 2004. http://in.news.yahoo.com/041224/48/2in9n.html. 
15.Economist. Oursourcing to India: Safety Matters. 2 Sepetermber 2004. http://www.economist.com/finance/displayStory.cfm?story_id=3160118

16.Fannin, Rebecca. India's Outsourcing Boom. Chief Executive. http://www.chiefexecutive.net/depts/outsourcing/198.htm. March 2004 Vol. 198.

17.Fjetland, Michale. "Global Commerce and The privacy clash.” The Information Management Journal. January/February 2002.

18.Fox Susannah. "Trust and privacy online: Why Americans want to rewrite the rules.” The Pew Internet \& American Life Project. 20 Aug 2000. http://www.pewinternet.org/pdfs/PIP_Trust_Privacy_Report.pdf. 2000. visited 22 Sep 04.

19.Geert, Hofstede. "Cultural and Organizations - Software of the Mind - Intercultural Cooperation and its importance for survival." McGraw-Hill. 1991.

20.Geert, Hofstede. Geert Hofstede Analysis. http://www.cyborlink.com/besite/hofstede.htm. 2003. visited 2 Oct 04 .

21.Google directory. http://directory.google.com/Top/Regional/Asia/India/Business_and_Economy/Shopping/ visited on 10 June 2004.

22.Harris and Westin. The Equifax Canada Report on Consumers and Privacy in the Information Age. Equifax Canada. 1992.

23.Harris Interactive for The Privacy Leadership Initiative (PLI). “A survey of consumer privacy attitudes and behavior.” 2001.

24.Harris Interactive for The Privacy Leadership Initiative (PLI). "Consumer Privacy Attitudes and Behaviors Survey - Wave II.” July 2001.

25.Harris Interactive. Harris Interactive Poll on Surveillance Issues. 1,010 respondents. March 19 2003. http://www.harrisinteractive.com/harris_poll/index.asp?PID=365, visited on 18 Aug 2004.

26.Harris Interactive. Privacy On and Off the Internet: what consumers want. Privacy \& American Business. 2001.

27.Harris, Louis and Associates and Alan F Westin. E-Commerce \& Privacy: What Net users want. Sponsored by Privacy \& American Business and Price Waterhouse, Inc. June 1998

28.Henry Michael. “International Privacy, Publicity and Personality Laws.” Reed Elsevier. pp 233 - 250. 2001.

29.Higher Secondary (HSC) Merit List for 2004. Fergusson College. http://www.fergusson.edu/notices/2004/june/hscmeritlist.asp. visited 15 Nov 2004

30.Indian Child. Population of India http://www.indianchild.com/population_of_india.htm. visited 10 Nov 2004.

31.Information and Privacy Commisioner, Ontario. A Report to the 22nd International Conference of Data Protection Commissioners. September 2000. http://www.ipc.on.ca/scripts/index_.asp?action=31\&P_ID=11425\&N_ID=1\&PT_ID=11 351\&U_ID=0. visited on 30 April 2005.

32.International Research Associates for the European Commission Directorate General Internal Market and Financial Services. Information Technology and Data Privacy. Eurobarometer 46.1. 1997.

33.International Telecommunication Union, "World Telecommunication Indicators 2003.” * STARS Version 4.2. Washington DC. USA.

34.International Telecommunication Union. ICT Free Statistics. http://www.itu.int/ITUD/ict/statistics/. visited 2 Oct 04

35.Johnson-Laird, P. “Mental Models.” Cambridge, MA: Harvard University Press. 1983.

36.Louis Harris \& Associates and Dr. Alan F. Westin. Health Information Privacy Survey. for Equifax Inc. 1,000 adults of the national public. 1993. 
37.Marcelo Ray and Khozem Merchant. Fortress India plan to combat online crime. The Financial Times. April 2005. http://news.ft.com/cms/s/ac5fb49a-abb9-11d9-893c00000e2511c8.html. visited 23 April 2004.

38.Mead, H George. "Mind, Self and Society." University of Chicago Press, IL. 1962

39.Milberg, Sandra J, et al. "Information privacy: Corporate management and national regulation.” Organizational Science, 2000 INFORMS Vol. 11, No. 1, pp 35 - 57. JanuaryFebruary 2000.

40.Milberg, Sandra J, et al. Values, personal information privacy and regulatory approaches. Communications of the ACM. December 1995/Vol.38, No.12.

41.Overby, Stephanie. India to Adopt Data Privacy Rules. CIO Magazine (September 1, 2003). http://www.cio.com/archive/090103/tl_data.html

42.Pandit, Sharvani. The law isn't much help. The Times of India. 15 Jan 2005. http://timesofindia.indiatimes.com/articleshow/991390.cms

43.Privacy International. Country reports - Republic of India.http://www.privacyinternational.org/survey/phr2000/countrieshp.html\#Heading3. visited 02 Oct 04.

44.Ribeiro John. Source code stolen from U.S. software company in India. Infoworld. Aug 05 2004. http://www.infoworld.com/article/04/08/05/HNcodestolen_1.html.

45.Roy Morgan Research. Privacy and the community. Office of the Federal Privacy Commissioner. July 2001. http://www.privacy.gov.au/publications/rcommunity.html.

46.Roy Morgan Research for The Office of the Federal Privacy Commissioner. Community Attitudes Towards Privacy 2004. http://www.privacy.gov.au/publications/rcommunity/index_print.html. visited 20 April 2004.

47.Suraiya, Jug and Vikas, Singh. The death of privacy. Times of India. 15 January 2005. http://timesofindia.indiatimes.com/articleshow/991395.cms.

48.The Joint Family, Encyclopedia Britannica Premium Service. http://www.britannica.com/eb/article?tocId=26070. visited 18 Oct 2004.

49.The World Fact Book. India. http://www.cia.gov/cia/publications/factbook/geos/in.html. visited on 25 Nov 2004.

50.Turner, Charles, and Elizabeth Martin, ed. "Surveying Subjective Phenomena.” New York: Russell Sage Foundation. 1984.

51.Westin Alan, Center for Social \& Legal Research. Bibliography of surveys of the U.S. Public, 1970 - 2003.

http://www.privacyexchange.org/iss/surveys/surveybibliography603.pdf. visited on 15 Aug 2004 